\title{
Naloxone does not impair conditioned inhibition of the rabbit's nictitating membrane response
}

\author{
DIANA E. J. BLAZIS and JOHN W. MOORE \\ University of Massachusetts, Amherst, Massachusetts 01003
}

\begin{abstract}
The possibility that the endogenous opiates are involved in conditioned inhibition of the nictitating membrane response was investigated by administering the opiate antagonist naloxone to albino rabbits. It was hypothesized that naloxone administration would increase responding to the inhibitory conditioned stimulus. However, no such increase was observed. These findings suggest that an alternate mechanism, possibly the brain-stem reward system, may be involved in conditioned inhibition.
\end{abstract}

Berthier and Moore (1980) reported that small electrocoagulation lesions of the periaqueductal gray (PAG) of the rabbit midbrain profoundly impair conditioned inhibition (CI) of the rabbit's nictitating membrane response (NMR). That study was an extension of earlier research conducted in this laboratory showing that electrical brain stimulation of the PAG, presented concurrently with the conditioned stimulus (CS), can suppress otherwise robust conditioned NMRs (Mis, 1977). Since the PAG has been implicated in opiate analgesia systems of the central nervous system (e.g., Watkins \& Mayer, 1982), we reasoned that endogenous opioids might play a role in CI.

Our working hypothesis was that the ability of a previously established conditioned inhibitor to suppress conditioned NMRs depends on the release of an endogenous morphine-like substance. Presumably, this substance is a neurotransmitter or neuromodulator originating in rostral brain-stem regions and acting on more caudal brain-stem regions that have been shown to be essential for the generation of conditioned NMRs (e.g., Desmond \& Moore, 1982). If this scenario is correct, then naloxone, an opiate antagonist, should impair the expressions of CI. Some support for this notion comes from recent reports that naloxone reverses morphine-induced suppression of conditioned NMRs in the rabbit (Mauk, Warren, \& Thompson, 1982) and increases resistance to extinction of the conditioned eye blink in the rabbit (Hernandez \& Powell, 1980).

\section{METHOD}

\section{Subjects}

Eleven New Zealand albino rabbits (Oryctolagus cuniculus), weighing $2.4-3.1 \mathrm{~kg}$, were obtained from a licensed local supplier.

This research was supported by NSF Grant BNS 8100322 . We are grateful to Endo Laboratories for their generous contribution of naloxone. Reprint requests should be sent to John W. Moore, Department of Psychology, Middlesex House, University of Massachusetts, Amherst, Massachusetts 01003.
They were caged individually in a colony room, maintained on ad-lib food and water, and kept under constant illumination.

\section{Apparatus}

Apparatus and procedures for establishing CI in our laboratory have been described elsewhere (e.g., Marchant, Mis, \& Moore, 1972). Basically, subjects received 100 trials/daily session with an intertrial interval of $15 \mathrm{sec}$. Half the trials consisted of presentation of a light CS $\left(L^{+}\right)$that was paired with the eye-shock unconditioned stimulus (US), and half the trials consisted of the same light compounded with a tone (LT-). The US was withheld on LT - trials. The two types of trials were programmed in a fixed random sequence such that no more than two trials of a given type occurred in succession. The duration of $\mathrm{L}$ and $\mathrm{T}$ was a constant 550 msec. On $\mathrm{L}+$ trials, the last $50 \mathrm{msec}$ of $\mathrm{L}$ was coextensive with the US. The light source for $\mathrm{L}+$ trials was a single incandescent lamp located behind a white translucent plastic screen, approximately $10 \mathrm{~cm}$ from the animal's face, in an otherwise dark chamber. The tone was a $1,200-\mathrm{Hz}$ sine wave of $85 \mathrm{~dB}$ (SPL).

The US was applied across $9-\mathrm{mm}$ wound clips sutured near to the inferior and posterior margin of the right eye; ac current level during the test phase was $1.5 \mathrm{~mA}$.

Testing for the effects of naloxone (vs. isotonic saline controls) began after animals attained a criterion of CI performance of giving conditioned NMRs on more than $90 \%$ of $\mathrm{L}+$ trials in a given session and less than $30 \%$ CRs to LT - in the same session. Conditioned NMRs were defined as $1-\mathrm{mm}$ deflections of the oscillographic recording pen occurring within the initial 500-msec period after CS onset. This corresponds to an NMR of approximately $.5 \mathrm{~mm}$.

\section{Testing}

Tests of effects of naloxone were conducted with groups of four animals each. When possible, animals were tested for CI performance following intravenous injection of naloxone and, on another session, isotonic saline as a control. Naloxone dosage was 1,3 , or $5 \mathrm{mg} / \mathrm{kg}$, dissolved in $1 \mathrm{ml}$ of saline. The order of injection was counterbalanced. Injections were into lateral ear veins, and the average time between injection and testing was $17 \mathrm{~min}$.

\section{RESULTS AND DISCUSSION}

CI performance during testing was assessed by an index computed as follows: The percentage of conditioned NMRs on LT - trials was subtracted from that for 
Table 1

Indexes of CI Performance (X 100) for Individual Animals for Last Pretest CI Session (P), Saline Control Session (S), and Naloxone Session

\begin{tabular}{ccccc}
\hline Subject & P & S & N & Naloxone* \\
\hline 1 & 70 & 51 & 90 & 1 \\
2 & 96 & 98 & 98 & 1 \\
3 & 81 & 86 & 83 & 1 \\
4 & 96 & & 100 & 1 \\
5 & 90 & 77 & & \\
6 & 66 & 68 & 69 & 3 \\
7 & 90 & & 92 & 3 \\
8 & 83 & & 89 & 3 \\
9 & 92 & 85 & 84 & 5 \\
10 & 79 & 45 & 89 & 5 \\
11 & 92 & 94 & 88 & 5 \\
Mean & 85 & 75 & 88 & \\
\hline
\end{tabular}

Note-Blank entries indicate that no injection was made. These instances arose when veins collapsed or deteriorated due to earlier injections. $\quad{ }^{*}$ Naloxone dosage in milligrams per kilogram.

$\mathrm{L}+$ trials, and the result was divided by the percentage of conditioned NMRs on L+ trials. An index value of 1.0 indicated perfect $\mathrm{CI}$ performance.

As Table 1 indicates, naloxone injections tended to enhance rather than to detract from CI performance, although repeated-measures $t$ tests yielded $t<1$ for comparisons of performance under naloxone vs. the saline-only control condition. Thus, naloxone did not impair CI performance as measured by an index based on the relative frequency of conditioned NMRs in the presence of the conditioned inhibitor; nor were any consistent differences in response topography (amplitude, latency, recruitment) noted between naloxone and control sessions, an observation consistent with Hernandez and Powell (1980).

Hernandez and Powell's (1980) demonstration of increased responding during extinction in rabbits treated with naloxone was obtained with a $1-\mathrm{mg} / \mathrm{kg}$ dosage of naloxone. We used this dosage, as well as two higher dosages, and yet we observed no significant increase in responding to LT-. One may consider the inhibitory response to LT - to be analogous to extinction of a conditioned response to the light component of the compound. However, $\mathrm{CI}$ is an active learning paradigm, requiring the animal to attend to the CSs presented; this is not necessarily true of extinction. Furthermore, we employed a shock level less than half as great as that used by Hernandez and Powell. If the endogenous opiate system is involved in CI, perhaps it is not activated until more aversive stimuli are presented.

Although the training and testing parameters in the present study differed in important ways from those employed by Hernandez and Powell (1980), they were highly comparable with those employed by Berthier and Moore (1980) and Mis (1977) in their reports implicating midbrain PAG in CI. As an alternative to the nowunlikely hypothesis that CI involves endogenous morphine-like substances, Berthier and Moore (1980) suggested that some other neural system might be involved. Specifically, it was suggested, on the basis of patterns of fiber degeneration following CI-disrupting lesions of PAG and nearby structures, that the dorsal noradrenergic bundle is a likely candidate for involvement in CI, as well as posterior hypothalamic regions known to be involved in reward effects (e.g., Bruner, 1967; Hupka, 1970). By this account, CI would be mediated by a brain-stem "reward" system, the logic for such a position being that a conditioned inhibitor is a signal that an aversive event, eye shock, is not forthcoming and is therefore the equivalent of a signal for reward (e.g., Dickinson \& Pearce, 1977). Further research is needed to address this hypothesis.

\section{REFERENCES}

Berthier, N. E., \& Moore, J. W. Disrupted conditioned inhibition of the rabbit nictitating membrane response following mesencephalic lesions. Physiology \& Behavior, 1980, 25, 667. 673.

Bruner, A. Self-stimulation in the rabbit: An anatomical map of stimulation effects. Journal of Comparative Neurology, 1967, 131, 615-630.

Desmond, J. E., \& Moore, J. W. A brain stem region essential for the classically conditioned but not unconditioned nictitating membrane response. Physiology \& Behavior, 1982, 28, 1029-1033.

Dickinson, A., \& PeArCe, J. M. Inhibitory interactions between appetitive and aversive stimuli. Psychological Bulletin, 1977, 84, 690-711.

Hernandez, L. L., \& Powell, D. A. Effects of naloxone on Pavlovian conditioning of eye-blink and heart rate responses in rabbits. Life Sciences, 1980, 27, 863-869.

HupKA, R. B. Electrical stimulation of the septum and hypothalamus as conditioned stimuli in the rabbit. Physiology \& Behavior, 1970, 5, 1355-1363.

Marchant, H. G., III, Mis, F. W., \& Moore, J. W. Conditioned inhibition of the rabbit's nictitating membrane response. Journal of Experimental Psychology, 1972, 95, 408-411.

Mauk, M. D., Warren, J. T., \& Thompson, R. F. Selective, naloxone-reversible morphine depression of learned behavioral and hippocampal responses. Science, 1982, 216, 434-436.

MIs, F. W. A midbrain-brain stem circuit for conditioned inhibition of the nictitating membrane response in the rabbit (Oryctolagus cuniculus). Journal of Comparative and Physiological Psychology, 1977, 91, 975-988.

WATKINs, L. R., \& MAYER, D. J. Organization of endogenous opitate and nonopiate pain control systems. Science, 1982, 216, 1185-1192.

(Received for publication July 14, 1982.) 